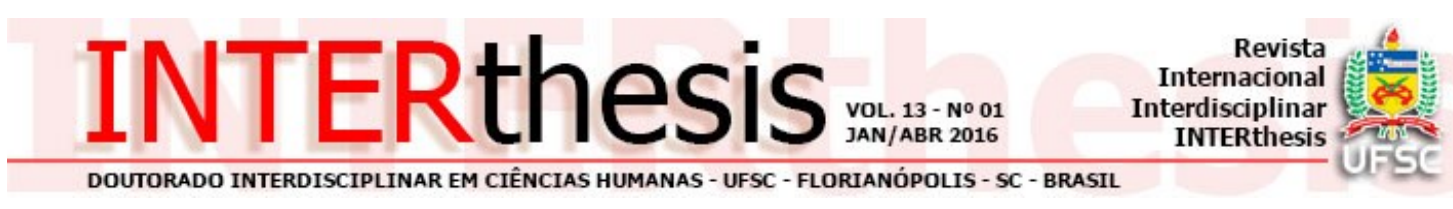

\title{
A MEMÓRIA NA PRISÃO: ENTRE A MASSIFICAÇÃO E A RESISTÊNCIA
}

Resumo:

José Mauro Oliveira Braz ${ }^{1}$ Fernanda Santos Curcio ${ }^{2}$ Francisco Ramos de Farias ${ }^{3}$

Este artigo tem como objetivo compreender como a instituição prisão consegue, por intermédio de suas dinâmicas, experiências e práticas disciplinares, funcionar de modo a provocar o nivelamento das diferenças subjetivas dos encarcerados pela assimilação das normas de convivência, em termos de submissão e obediência a cultura prisional. Como metodologia utilizada, realizou-se o levantamento bibliográfico de obras que auxiliassem na construção desta discussão, onde autores como Foucault, Goffman, Thompson e Althusser direcionaram o referido trabalho. $\mathrm{O}$ fenômeno da massificação subjetiva se faz presente na medida em que a instituição atua no sentido de tentar produzir semelhantes experiências nos encarcerados, transformando-as em vestígios de memórias e lembranças. Desse modo, a prisão, como qualquer outro lugar de memória, conduz seus encarcerados de acordo com um conjunto de determinações estabelecidas para a transmissão da disciplina e controle. Porém, o ambiente prisional que atua na busca da padronização subjetiva está fundamentado em contradições e de correlações de forças que dão espaço a resistência. Configurando, assim, não apenas a preservação da memória do espaço instituído, como também a produção de arranjos, ou melhor, uma modalidade de memória em termos de possíveis dobras que se impõe ao poder desta instituição.

Palavras-chave: Prisão. Instituição. Memória. Subjetividade. Resistência.

\section{INTRODUÇÃO}

A instituição prisão, como qualquer outra, apresenta como característica principal a condição de reprodução, logo, as ações que se desenvolvem neste cenário concernem a dinâmicas e padrões repetitivos, que se constituem para seus atores como hábitos. A questão central desse espaço social é a legitimidade, e para que isso aconteça é necessária uma incessante reprodução das práticas sociais,

\footnotetext{
${ }^{1}$ Mestrando em Memória Social pela Universidade Federal do Estado do Rio de Janeiro, Rio de Janeiro, RJ, Brasil. Pesquisador voluntário do projeto A construção da Memória Social da Educação Prisional do Estado do Rio de Janeiro, Rio de Janeiro, RJ, Brasil. E-mail: jmobraz@yahoo.com.br

2 Mestranda em Memória Social pela Universidade Federal do Estado do Rio de Janeiro, Rio de Janeiro, RJ, Brasil. Bolsista do CNPq. E-mail: nanda fsc@hotmail.com

${ }^{3}$ Doutor e Mestre em Psicologia pela Fundação Getúlio Vargas, Rio de Janeiro, RJ, Brasil. Professor do Programa de Pós-Graduação em Memória Social da Universidade Federal do Estado do Rio de Janeiro, Rio de Janeiro, RJ, Brasil. Bolsista Produtividade PQ 2. Pesquisador da FAPERJ E-mail: frfarias@uol.com.br
} 
que são transmitidas permanentemente aos sujeitos encarcerados neste lugar. Diante disso, surgem algumas questões: Quais são as memórias que são referências da prisão? Quais atores fazem parte deste espaço? Como se realiza o processo de subjetivação diante da memória que se constrói no universo prisional? Existem fronteiras entre a instituição prisão e os aprisionados? Até em quais circunstâncias a prisão reitera memórias que são construídas pelos encarcerados?

Nesse sentido, alude-se que qualquer instituição, longe de ser um fenômeno individual, é construída para e por atores sociais. Isso significa dizer, que a mesma surge como resposta a diferentes demandas e problemas da sociedade. Seguindo esta lógica para que uma instituição se mantenha e se reproduza ela necessita de uma memória convergente a ela.

A prisão, bem como outras instituições, apresenta mecanismos de controle social que estabelecem regras e normas de conduta que garantam o seu funcionamento e a operação de suas ações reprodutoras. Por isso, o estudo sobre esta realidade é enriquecido pelo aporte teórico da memória social, uma vez que a instituição reitera constantemente protocolos que deverão ser repetidos, transformando-se em hábitos sob o suporte da memória. A instituição luta pela preservação da sua legitimidade e regularidade.

Isto não significa dizer que a instituição não traz consigo mudanças. A história está sendo constantemente reescrita, e sempre com as interferências do passado. No caso da prisão não seria diferente, pois a mesma, ao longo do tempo, sofreu diversas transformações, até assumir a forma que hoje é conhecida. A Prisão é uma instituição social de grande complexidade que encerra diferentes modalidades de saberes, de modo que, qualquer abordagem considerando uma de suas singularidades, produz um conhecimento parcial e, muitas vezes, distorcido da realidade.

Sendo assim, esta instituição corresponde a uma condensação de diferentes camadas de ações sociais, razão pela qual é objeto de uma análise crítica. Isso significa dizer que qualquer alusão ao sistema prisional deve considerar o tópico em foco, quem o está abordando e de qual lugar é feita a interpretação.

Historicamente aqueles que incomodam eram e ainda são inevitavelmente segregados do contexto social. Inicialmente a prisão não era um espaço para se cumprir uma pena ou lugar de aplicação de um castigo: era utilizada para acautelar

R. Inter. Interdisc. INTERthesis, Florianópolis, v.13, n.1, p.01-20 Jan-Abr. 2016 
o réu ou condenado até a punição, que poderia ser um castigo corporal, a morte, o degredo, a desapropriação de bens materiais, a exílio forçado ou a amputação de partes do corpo. Ao percorrer a história dos segregados, percebe-se que, na Idade Média, houve uma maior preocupação com a questão da segregação, principalmente em virtude do surgimento e da rápida disseminação da lepra que incluía praticamente todas as doenças de pele. Sob o argumento de evitar a disseminação da doença, são criados os leprosários, local construído com o objetivo de separar os leprosos do restante da população.

Ao final da Idade Média a lepra desaparece do mundo ocidental (FOUCAULT, 1996), e com isso tem origem uma série de estabelecimentos desprovidos de uso. Se estes antes tinham o propósito de segregar, poderiam ser mantidos para a mesma finalidade, mudando apenas a categoria do segregado. Diante deste cenário, os leprosários, passaram a ser locais de exclusão destinados aos portadores de doenças venéreas, aos pobres, aos vagabundos, às prostitutas, aos alcoólatras e aos loucos, sob a nova denominação de hospital geral. Esses sujeitos que expressam 'um modo de ser' diferente, geralmente, deixados a esmo por suas famílias, foram institucionalizados como portadores de traços como a alienação ou desaprovados moralmente em função de vagabundagem. Fossem calabouços, prisões, hospitais gerais, tais espaços eram usados pela classe dominante para encarcerar e "o encarceramento era, acima de tudo, um método que almejava o controle de populações divergentes e dependentes" (WACQUANT, 2008).

Cabe ainda ressaltar, acerca do contexto social vivido na Europa que, de acordo com Foucault (1996) durante o século XVII a Europa estava diante de uma crise econômica, com altas taxas de desemprego, moeda escassa e baixos salários. Atribuíam esta situação aos vagabundos, aqueles pobres que não se dedicavam ao trabalho, mas também a mendicância ou a roubos. Para "limpar" a sociedade desta "infestação" foram criadas diversas casas de internamento. As mesmas não eram instituições médicas, na verdade, eram uma estrutura semijurídica que abrigavam os pobres e os miseráveis onde os loucos eram confinados. Neste cenário, tanto o executivo, quanto o judiciário poderiam dar ordens de reclusão. Porém, este sistema fracassou, uma vez que não reduziu o número de desempregados, e ainda era muito dispendioso para o Estado, fazendo com que seja extinto no início do século XIX (CASTEL, 1978).

R. Inter. Interdisc. INTERthesis, Florianópolis, v.13, n.1, p.01-20 Jan-Abr. 2016 
É interessante observar que o Hospital Geral, instituição criada para ser espaço de reclusão, abrigava diferentes categorias de indesejáveis à sociedade, excluindo-se os criminosos que não teriam esse destino. Este não se misturava com outras categorias de sujeitos socialmente discriminados negativamente. Por isso, a prisão, desde os seus primórdios, é o espaço específico criado para conter aqueles que transgridem determinadas normas sociais.

Muitas ações direcionadas aos "anormais" tiveram uma modificação no fim do feudalismo. Durante esta fase da história da humanidade, diversos pensadores se empenharam a criticar severamente o sistema punitivo da época. Beccaria (2001) chega a sugerir um novo sistema que se assentava em princípios liberais como o do Contrato Social. Os homens livres deveriam viver em harmonia, em que cada um responderia por seus atos, e cederia parte de sua liberdade para que pudesse desfrutar o resto desta com maior segurança. Daí a necessidade de estabelecimento de pactos e acordos como condição necessária a vida coletiva. É sobre esta união de reduzidas liberdades que se mantém o direito de punir, logo, o crime sendo compreendido como o desrespeito ao pacto social, deveria receber uma pena proporcional ao delito cometido. Nesse sentido, o contexto das práticas jurídicas criou uma gradação de crimes, colocando-os em uma escala valorativa definida por critérios de gravidade.

A passagem do feudalismo para a sociedade moderna, sustentada por valores burgueses, deu-se no século XVIII e, em meados deste século, origina-se a medicina social, que se apresentava como um instrumento biopolítico para controlar os homens, de maneira a possibilitar a manutenção do capitalismo industrial (FOUCAULT, 1979), transformando assim o a prática do encarceramento "em uma maneira de neutralizar uma parte da população excedente, que não é necessária à produção. " (SEQUEIRA, 2004). Além disso, o século XVIII foi conhecido como o "século das luzes", e dentre as ideias que transitavam à época, surgiu o princípio que compreendia a liberdade como um bem inestimável, sendo assim, o sujeito que transgredisse a ordem social, poderia ser privado deste bem, que é o único bem comum ao homem livre.

Posteriormente, surge o movimento higienista, que traz o surgimento do mito das "classes perigosas", compreendendo que as pessoas que fazem parte das mesmas possuíam características próprias de seus segmentos sociais. Este

R. Inter. Interdisc. INTERthesis, Florianópolis, v.13, n.1, p.01-20 Jan-Abr. 2016 
movimento se apresenta como a adoção do modelo médico nos fenômenos humanos, físicos e sociais (JACÓ-VILELA, 2005). A suposição da existência destas classes funestas fez com que o Estado organizasse aparatos técnicos que intervissem neste fenômeno.

É neste contexto, esclarece Dornelles (1988), que o aparato judiciário, sugestionado pela Ciência Positivista, requisita a Psiquiatria para explicar o limiar biopisíquico dos crimes, surgindo assim, a Criminologia Positivista. Esta, através das contribuições do médico psiquiatra Lombroso, faz surgir a ideia do criminoso nato e do crime com um resquício atávico do homem de barbárie, assinalando um estado de involução. De acordo com o mesmo, havia uma correlação entre a propensão para a criminalidade e as características físicas dos indivíduos, cabendo ao Estado, então, utilizar-se de medidas de segurança para controlar as pessoas "naturalmente" perigosas que não teriam nenhuma chance de fazer parte da convivência social.

Este é o momento do surgimento das sociedades disciplinares, como salienta Foucault (1979). A partir deste século, emerge um insólito mecanismo de poder que fomenta a aquisição do tempo e trabalho dos homens, como forma de correção e de purificação, já que a ociosidade passou a ser considerada um vício que deve ser combatido. Este poder disciplinar se materializa na contínua vigilância que afetará não só a sociedade como um todo, mas também a esfera prisional, neste último, tal concretização se efetiva mediante a ampla disseminação do projeto arquitetônico idealizado por Bentham (2008) que apesar ter pensado um projeto que serviria de "plano para uma casa de inspeção penitenciária" (BENTHAM, 2008, p.20), este se entendeu à muitas instituições onde o controle e a vigilância eram necessários. Além das prisões, onde as prerrogativas citadas são uma necessidade natural ao objetivo da instituição, pode-se mencionar as escolas e os conventos, locais que não possuíam a premissa da punição, mas que se utilizavam da vigilância para ordenar o dia-a-dia e as atividades desenvolvidas em seus espaços.

As novas estruturas dos espaços prisionais centradas no controle e vigilância tinham por objetivo a correção do preso mediante o acompanhamento de medidas disciplinares para o corpo (isolamento físico) e para a mente (ser visto sem ver), para com isso reinserir na sociedade aquele que transgride uma de suas normas (AGUIRRE, 2009). A substituição do castigo físico pela pena com privação de 
liberdade, fundamentada em preceitos considerados científicos, apresenta-se como a principal motivação para a criação das prisões modernas.

A passos lentos a humanidade começou a caminhar na direção do tratamento do criminoso pelo viés dos direitos humanos. Assim diminuíram os castigos de caráter físico, e aumentaram as punições de caráter moral. Contudo, deve-se salientar que para Foucault (1987), a real finalidade da prisão é a produção da delinquência e a repressão seletiva da criminalidade, que se concentra na contenção das camadas sociais mais desfavorecidas.

Levando-se em consideração os elementos expostos, pode-se aferir que a prisão, como qualquer outra instituição, surge como criação, como uma solução de alguma adversidade do seio social. Mas, a mesma não é definitiva, é na verdade um processo que se constrói ao longo da história. Assim, para entender e se debruçar sobre este espaço é necessário trazer à luz o encadeamento de seus discursos, técnicas e ações que se fundamentam e se materializam em práticas sociais dos sujeitos que nele estão confinados.

\section{METODOLOGIA}

Utilizando de uma perspectiva dialética - cujos fatos e fenômenos sociais não podem ser considerados descolados de um contexto econômico, político, cultural e social -, este trabalho não pretende construir um conhecimento sobre esta realidade tão somente pelo enfoque histórico ou sociológico, ou o oposto, direcionar o estudo exclusivamente pela perspectiva individual. $\mathrm{O}$ que se propõe, é conceber a realidade a partir da memória social, esta enquanto um campo de análise que possibilita as investigações e a construção de um conhecimento sobre as relações de poder, a particularidade do sujeito, a influência da transmissão de valores e culturas, os modos de ser, e também a criação.

Diante de um processo sistemático e objetivo de investigação, foi realizado um estudo exploratório, levantando o material bibliográfico que auxiliasse na construção do aporte teórico capaz de galgar conhecimentos que vão em direção à complexidade do fenômeno ora trabalhado. Este material se baseou nas contribuições dos autores como Foucault, Goffman, Thompson e Althusser, entre outros.

R. Inter. Interdisc. INTERthesis, Florianópolis, v.13, n.1, p.01-20 Jan-Abr. 2016 
Não obstante, é importante considerar que não se pode tomar qualquer teoria como uma verdade absoluta, uma vez que nenhuma está fora dos limites históricos e sociais que as sustentam. Quaisquer perspectivas devem ser utilizadas como uma ferramenta de análise dos fenômenos sociais, estando sempre no movimento de autoconstrução, que não chegando a um desenlace, certamente se voltará a novos questionamentos e direções.

\section{A INSTITUIÇÃO PRISÃO: DOCILIZAÇÃO E PADRONIZAÇÃO DE SUBJETIVIDADES}

Todo contexto social é constituído por instituições. A noção de instituição parte da concepção de que esta é um mecanismo de proteção da sociedade, no qual se encontra um conjunto de regras e procedimentos padronizados socialmente, aceitos e sancionados pela própria sociedade. A importância das instituições concretiza-se no fato de estas possuem a capacidade de conservar a organização social e satisfazer as necessidades de determinados grupos que as compõe. São, portanto, instâncias conservadoras por essência e atuam no sujeito com a intenção de manter a ordem. Na maioria das vezes os sujeitos que compõem as instituições, estão alheios ao seu funcionamento e à sua função social.

Althusser (1918) ao se voltar para a problemática acerca das instituições, define-as como aparelhos do estado, apresentando a divisão entre aparelhos repressor do estado e aparelho ideológico do estado. O primeiro tem por função garantir a ordem da chamada relação de produção (ALTHUSSER, 1918) por intermédio de instrumentos coercitivos e majoritariamente físicos. Os aparelhos ideológicos do Estado buscam da mesma forma, conservar as relações de produção que atravessam a sociedade e o fazem também por intermédio de métodos coercitivos, porém estes são majoritariamente ideológicos, ou seja, apresentam-se na esfera do discurso e das ideias.

Apesar de serem instituições que atravessam a sociedade e tendem a um certo fechamento, na intenção de conservar a ordem, todas elas possuem um grau de abertura, às vezes extenso, às vezes não. Esta abertura permite que os sujeitos que integram as instituições possam circular e assim instalar-se nas que vão de encontro às noções de conforto, ou construções ideológicas acerca do melhor 
funcionamento da sociedade. Outras instituições apesar de conservarem determinado grau de abertura, exigem um maior comprometimento de seus membros, restringindo um pouco mais o fluxo social existente entre o seu interior e o meio social. De um modo ou de outro, as instituições exigem de seus participantes a relação de pertencimento, oferecendo-lhes uma espécie de proteção.

Assim como as instituições tendem a conservar certo grau de abertura, elas igualmente conservam certo grau de retraimento. Um tipo de instituição específica e com características marcantes de fechamento são as instituições totais (GOFFMAN, 1974). Tratam-se de instituições que caracterizam seu fechamento por uma barreira em relação ao mundo externo, por intermédio da proibição de saídas. Essas proibições podem funcionar por intermédio de coerção física. Tais instituições podem ser mais especificamente definidas como "um local de residência e trabalho onde um grande número de indivíduos com situação semelhante, separados da sociedade mais ampla por considerável período de tempo, levam uma vida fechada e formalmente administrada" (GOFFMAN, 1974, p.11). Em qualquer que seja o tipo de instituição, o contexto das trocas e consequentemente a transmissão de experiências existirá sempre, configurando-se assim um espaço de conservação e criação de memória.

Para compreender como se realiza o fenômeno da memória no espaço institucional, deve-se, em princípio, considerar que este universo apresenta condições essenciais de saber-poder. Esta afirmação corrobora as relações entre o saber e o poder desenvolvidas por Foucault (1979), em sua obra Microfísica do poder. De acordo com o autor, o poder é exercido, é ação que se produz nas correlações de força.

O saber-poder se materializa no meio social comportando o jogo do lembrar e esquecer, onde as instituições conservam ou esquecem num sistema de racionalização que vá de encontro ao que é estabelecido. Assim, além de selecionar as lembranças já constituídas, age também na produção do o que lembrar. Isso é necessário para a manutenção de qualquer instituição, pois a sua questão primordial, como já apontado anteriormente, é a legitimidade.

A memória de uma instituição, como bem esclarece Costa (1997), encontrase num movimento de informações que produzem práticas discursivas ativas, gerando uma permanente inter-relação entre o instituído e o instituinte. Ressaltando 
neste momento que não existe uma oposição entre o instituído e o instituinte, pois na verdade esse processo se configura numa relação dinâmica, onde as duas forças coexistem e se inter-relacionam.

Costa (1997, p. 45) salienta que o ato de reproduzir da instituição produz memórias, onde a memória institucional se mantém nesse eterno movimento do que é instituído e o que vem sendo transformado - o instituinte. Este jogo pode ser compreendido sob duas perspectivas, a de uma memória-hábito que conserva e memoriza as condutas e comportamentos dos sujeitos sociais; ou como uma memória-arquivo, onde "determinadas regras e informações devem ser constantemente recuperadas, para a manutenção de determinada ordem vigente".

De acordo com Bergson (1990) o hábito é um tipo de memória, e por se tratar de um dispositivo que todos os seres humanos fazem uso, acaba por instaurar o que deve ser lembrado ou não. Berger e Luckmann (2004) compreendem que toda e qualquer atividade humana está sujeita ao hábito, sendo este reproduzido a partir das instituições. Sendo assim, o hábito de repetição no âmbito carcerário é uma necessidade a ser apresentada cotidianamente para preservar a sua regularidade.

Deleuze (2005, p. 41), através das contribuições de Foucault, percebe a prisão como uma "formação de meio (o meio 'carcerário'), e uma forma de conteúdo (o conteúdo é o prisioneiro) ". Sendo assim, a visibilidade desta instituição se apresenta com os discursos, ou enunciados do direito penal, assim:

[...] a instituição formaliza funções, integra saberes, produz substâncias formadas, que são os agentes institucionais por ela legitimados: na escola, o estudante; na medicina e no hospital, médicos e doentes; na prisão, o prisioneiro; no hospício, o louco; nos campos de trabalho, o trabalhador (COSTA, 1997, p. 84).

Ricoeur (2007) ajuda nesta compreensão, ao trazer para o campo de estudo o fenômeno da "memória manipulada", que se constrói e se reproduz no campo das relações de poder. A manipulação da memória está expressa em processos ideológicos, fundamentais para a construção de narrativas, sendo estas necessárias para a construção e modificação das subjetividades.

De acordo com Fonseca (2006), a prisão, no uso de violência simbólica representada nas práticas disciplinadoras, age no sentido de provocar a anulação dos anseios e desejos pessoais. Desta forma, este espaço apresenta diversos tipos de segregação,

R. Inter. Interdisc. INTERthesis, Florianópolis, v.13, n.1, p.01-20 Jan-Abr. 2016 
[...] a mais aparente é a que separa os encarcerados do restante da sociedade. No entanto, há outras menos perceptíveis, como a divisão dos presos dentro do próprio ambiente prisional, distribuindo-os em celas, galerias, solitária, bem como limitando ou autorizando o acesso dos presos aos demais espaços da prisão, tais como o refeitório, corredores, oficinas, etc. (BARCINSKI; CÚNICO, 2014, s/p).

Nas prisões existe um grupo enorme de internos e uma pequena equipe de supervisão. O internado vive na instituição e tem contato restrito com o mundo extramuros, não possuindo, muitas vezes, a possibilidade de enviar ou receber uma simples carta sem passar pelo crivo do aparato de supervisão. Isto se dá porque o seu objetivo é excluí-lo do meio social, a fim de que o internado absorva totalmente as regras da instituição. Sendo assim, ao ingressar em uma instituição dessa natureza, mediada por rigorosas relações de poder, o sujeito tem que se submeter, como condição de garantia da própria sobrevivência.

De acordo com Foucault (1987, p. 6), a prisão "se fundamenta também em seu papel, suposto ou exigido, de aparelho de transformar os indivíduos". Nesta realidade o sujeito passa por um processo de anulação do eu (GOFFMAN, 1974), que começa com sua recepção, por meio de rituais, conhecidos, como rituais de "boas vindas", onde a equipe de supervisão e o grupo de internados, ou ambos, procuraram deixar de forma bem clara ao "novato" a sua situação de fragilidade e dependência em relação àqueles que já se encontram na instituição. Trata-se de um processo dirigido aos condenados que, antes de serem destinados às suas celas, passam uma semana ou mais em estado de confinamento, denominado de triagem, que funciona para conscientizar o preso da obediência às normas da instituição e da adesão à cultura prisional.

Geralmente, nesse intervalo de tempo é produzida a ambientação do encarcerado à prisão pelo fornecimento de elementos para a construção da identidade de preso e a tentativa de apagamento de certas nuances identitárias construídas no contexto social da vida em liberdade. Neste universo carcerário apresentam-se um conjunto de proibições e normas que prescrevem como os prisioneiros dever conduzir as suas ações, detalhando como deve ser desenvolvida a rotina inflexível destes sujeitos. Por outro lado, em divergência a esta realidade austera, existem também na instituição prisão um reduzido número de vantagens e privilégios conquistados em troca de obediência e respeito às imposições. 
O homem, ao ser preso, não é mais um sujeito, ele passa a ser parte da instituição na qual se encontra e deverá obedecer à todas as suas regras da mesma sem qualquer hesitação. Desse modo, acontece a institucionalização do preso com o nivelamento de suas diferenças identitárias e a tentativa de um apagamento do Eu, ou seja, o preso ao ser desapropriado de seus documentos e receber um número, passa a ser o segmento de uma série de iguais. Caso não o faça, passará por processos de adaptação forçada, sem ter alternativas de seguir outros caminhos. É muito comum o enlouquecimento ou o uso abusivo de antidepressivos e drogas ilícitas como formas de oposição ao condicionamento imposto pela instituição prisional.

Cabe ressaltar que o condicionamento, pode ser aplicado ao homem tanto pelos próprios prisioneiros, que detém um mecanismo de poder sobre aqueles que ingressam e que estão na mesma condição, quanto pela equipe gestora da instituição que prima pela exposição das regras a serem seguidas e devidamente cumpridas. Obviamente os gestores prisionais interpretam qualquer transgressão a uma dessas regras como uma solicitação de castigo e punição, alegando tratar-se de um sujeito que não se adapta ao sistema, sendo identificado, então, como um mau preso. $\mathrm{O}$ importante é que a máquina institucional não interrompa a rotina de suas atividades. Esse é o processo conhecido como prisonização, o qual consiste em o sujeito adequar-se completamente as regras da instituição prisional. Porém até que a instituição alcance esse estágio em que o preso internalize a cultura prisional serão aplicados vários procedimentos de anulação subjetiva (THOMPSON, 1980). Desta forma, busca-se, gradativamente, que o preso abra mão de seus valores, bem como das lembranças da vida em liberdade, para internalizar as normas da prisão de forma bem rápida.

A impermeabilidade da prisão, se faz necessária para a manutenção da moral, nesse sentido, as referências como a família, o meio de trabalho e o bairro onde reside, por exemplo, devem ser afastados do preso no intuito de torná-lo inteiramente dependente da instituição onde se encontra. No universo institucional,

[...] há uma longa duração das práticas sociais, organizadas e codificadas em estratificações sedimentadas nas camadas do tempo. A instituição lança mão de uma tendência do ser humano, que é o hábito de contrair hábitos. $\mathrm{A}$ memória-hábito é um recurso que a instituição dispõe, e de forma análoga produz rotinas, que devem ser repetidas (COSTA, 1997, p. 138).

R. Inter. Interdisc. INTERthesis, Florianópolis, v.13, n.1, p.01-20 Jan-Abr. 2016 
Todas as tramas do dia-a-dia, as influências e funções exercidas por cada ator social presente na instituição prisão são regidas por um princípio de convergência que é ponto central dos estudos de Foucault (1987): o poder. Mais especificamente no caso da instituição abordada o poder disciplinar. É sabido que para Foucault, o poder não é uma coisa, nem uma propriedade, ele não está localizado somente no governo ou no estado. O poder não pode ser definido somente em um lugar, indivíduo ou instituição, muito pelo contrário, o poder é apresentado como sendo uma trama, uma rede que está difusa transversalmente em toda a sociedade.

A disciplina é um poder individualizante, e assim o é, pois é exercida sob o corpo de cada sujeito. O ponto de destaque da disciplina é que apesar de ser uma ação externa ao sujeito, ela se instala no mesmo, alterando o seu status moral, sua condição social e principalmente subjetiva. Para que o poder disciplinar seja efetivo naquilo que se propõe, é necessário haver um controle sobre os corpos a serem disciplinados. Daí decorre a necessidade do confinamento em instituições, sejam totais ou não. As instituições de confinamento são instituições de sequestro, que acabam por capturar os sujeitos para dentro de si e assim disciplinarem os mesmos.

A grande questão acerca do poder exercido nas prisões, e nesse caso o poder disciplinar, é que ele age no sentido de modificar o sujeito e o faz assujeitar-se a esta instituição. Porém, para que esta atue, Costa (1997, p. 41) salienta que "toda uma memória é colocada em funcionamento, como um memento, um lembra-te das tuas obrigações e dos teus limites". Porém, é importante ressaltar que a submissão funciona de forma bastante paradoxal, pois se de um lado revela, no dominado, o poder do dominador, por outro, possibilita formas de resistência que culminam na produção de subjetividades.

De acordo com Guattari \& Rolnik (1996) a subjetividade é uma produção constante. Tal produção surge a partir dos encontros e momentos com o outro, onde este outro pode ser lido como um ser social, um outro social, porém também poder ser lido como natureza, ocasiões, acontecimentos, enfim, qualquer coisa que venha a produzir consequências e efeitos nas mais diversas formas de viver e nos corpos. Tais efeitos difundem-se por meio de múltiplos componentes de subjetividade que estão em circulação no campo social. Pode-se entender que a subjetividade é um processo de produção no qual comparecem e participam múltiplos componentes. 
Tais componentes são oriundos da apreensão parcial que o sujeito realiza, de forma fixa e longínqua, de um conjunto de elementos dos mais diferentes tipos e classificações que estão presentes no contexto social. Logo, sabe-se que ideias, sentidos e valores, são registrados de forma singular, e servindo assim de matéria prima para a expressão dos afetos vividos nesses encontros.

\section{MEMÓRIA E PRISÃO: ENTRE A SUBMISSÃO E A RESISTÊNCIA}

Como tratar do universo prisional e de seus encarcerados sem se dedicar à memória?

O ser humano é constituído de memórias, não apenas social, mas também institucional. As vivências, informações e experiências que se formam ao longo da vida, são impressas em sua consciência e inconsciência. Logo,

\footnotetext{
[...] vistas através das lentes do tempo, as instituições refletem as formalizações das culturas, daquilo que as diferentes sociedades cultivam como maneiras de pensar: hábitos, usos, costumes, comportamentos, etc. Aquilo que instituem. Todo esse percurso nas esferas da vida social tem deixado vestígios das mais variadas ordens. Visíveis ou invisíveis, os produtos da experiência do homem em sociedade também constituem legados/memórias (COSTA, 1997, p. 4).
}

A partir dessas considerações adentra-se ao universo das prisões que têm como suporte o poder de produção de sujeitos submissos e obedientes. O poder disciplinar, neste contexto, utiliza-se de uma vigilância contínua e funcional, normalizando e impondo leis que devem ser memorizadas.

A memória, então, pode ser compreendia como um mecanismo de imposições, a partir do momento que reproduz valores e interesses dominantes. Este fenômeno é desenvolvido por Gondar (2000), para quem a memória pode ser efetivamente um instrumento de poder. Para travar esta discussão, a autora traz para o campo de debates as contribuições de Foucault, nas quais o mesmo entende que o poder além de selecionar as lembranças já constituídas, age também na produção daquilo do que deve ser lembrado.

Ressalta-se que para Foucault a produção de subjetividade é uma construção de memória. Mas cabe pontuar que o sujeito, diante das imposições sociais, responderá de maneira única e distinta, "constituindo processos de criação de si, isto 
é, processos de subjetivação, que escapam àquilo que os códigos estabelecem" (GONDAR, 2000, p. 34).

A prisão, no ato de formalizar e internalizar regras de comportamento e de conduta, primeiramente as fixam nos sujeitos para posteriormente reproduzi-las. Por outro lado, neste incessante movimento de repetição que realimenta a ordem e o funcionamento da instituição, ela acaba por ceder espaço para mudanças, onde a memória se faz presente em dois momentos: na repetição e representação, como na interrupção, na descontinuidade, e no aparecimento do novo (COSTA, 1997).

Assim, o poder produtor da submissão é também um meio de possibilidade no processo de formação do sujeito, na medida em que lhe proporciona condições para sua existência, de modo a poder revelar a trajetória de seu desejo. Como afirma Foucault (1987), o poder não é apenas aquilo a que o homem se opõe, visto ser também aquilo de que o homem depende, em sua existência, no sentido da produção de movimentos que expressam aquilo que cada um é em termos de singularidade. Mesmo que consideremos a sujeição como o processo de subordinarse ao poder, temos também que considerar que é o poder que possibilita o advento do sujeito, em termos de construção subjetiva. Dito de outra forma, o mesmo movimento do poder que produz a sujeição é responsável pela produção subjetiva, pois "el poder que em um principio aparece como externo, presionado sobre el sujeto, presionando al sujeto a la subordinación, asume uma forma psíquica que constituye la identidad del sujeto" (BUTLER, 2011, p. 13).

Consequentemente, afere-se que o poder atua no sujeito de duas maneiras distintas: uma, no contexto da submissão; outra, como uma condição que possibilita ao sujeito construir suas teias de relações, constituindo assim um dos mecanismos de produção de subjetividade, criando a possibilidade da construção de resistências às tensões impostas pelo espaço carcerário. É necessário ressaltar que, no primeiro caso, o poder funciona como uma forma de exterioridade ao sujeito; enquanto que, no segundo, funciona como efeito voluntário de sua posição subjetiva.

O universo prisional na qualidade de uma engenhosa máquina óptica, que tudo consegue ver sem ser vista, produz o sujeito encarcerado. Em termos desta posição, o sujeito pode manter-se massificado dentro desta instituição, produzindo a manutenção do poder, ou lutar para expressar sua singularidade. Esta singularidade 
é uma forma de resistência aos mecanismos que nivelam as suas diferenças, na intenção de anulá-las ou tornar os homens iguais.

A produção de subjetividades, da qual o sujeito é um efeito provisório, mantém-se em aberto uma vez que cada um, ao mesmo tempo em que acolhe os componentes de subjetivação em circulação, também os emite, fazendo dessas trocas uma construção coletiva viva. A difusão desses componentes se dá a partir de uma série de instituições, e é nessa dinâmica mutante de ações e acontecimentos que os processos de subjetivação vão tomando forma.

A memória, aqui, é compreendida como uma resistência, ou como "uma aposta do porvir", onde a criação não combate o poder ou se assujeita a ele. Ela, na verdade, funciona como uma dobra que se dá por cima da força, irrompendo-se o diferente e original, que ultrapasse essa dominação (GONDAR, 2000). Em vista disso,

Ao contrário do que costumamos pensar, nós somos e fazemos as instituições. E a memória institucional é o reflexo dessa trajetória, não como mimesis, mas um cristal com suas múltiplas e infinitas facetas. É também uma memória histórica, efeito dos condicionamentos e das formações históricas. Ao invés de ficarmos no registro das causas, é preciso lançar as ideias no seio das indeterminações, onde é necessário escolher, afirmar a divergência produzida pelo próprio problema. A resolução do problema então será a criação (COSTA, 1997, p. 146).

Desta forma, a prisão, como toda instituição, é uma estrutura, uma concretude, um corpo, logo ela é finita. É um poder que se encontra numa relação carregada de conflitos com outros poderes. Estas possuem a capacidade de transformação. Assim, os componentes ganham importância coletiva e são atualizados de diferentes maneiras no cotidiano de cada sujeito. Eles podem ser abandonados, modificados, reinventados e criados em um movimento de misturas e conexões que não é interrompido.

\section{CONCLUSÃo}

Diante do que foi apresentado ao longo desta reflexão, pode-se aferir que as instituições são construídas e reproduzidas pelos sujeitos que compõem o meio social. A memória institucional além de ser uma memória histórica, é também social, apresentando-se como um produto do meio que ao mesmo tempo exerce influências sobre este espaço e nos atores sociais nele envolvidos. A memória, como já

R. Inter. Interdisc. INTERthesis, Florianópolis, v.13, n.1, p.01-20 Jan-Abr. 2016 
apontado, é fundamental para o funcionamento de qualquer instituição, uma vez que possibilita a sustentação do seu status quo, selecionando elementos que sejam fundamentais para a manutenção da memória institucional.

Porém, para que isso aconteça, além de se apoiar nos sujeitos que a compõe, necessita também de um jogo de produção e reprodução que extrapole os limites institucionais. Este fenômeno se fundamenta a partir dos mecanismos de controle que formam as regras, normas e padrões que promovem as suas funções reprodutoras.

A prisão, instituição na qual este trabalho se dedica, se mantém na repetição de hábitos que reproduzem memórias de subalternidade, por meio da repressão, da perda do contato com o mundo exterior (ou da limitação deste contato), do controle das atividades e na vigilância do cotidiano dos sujeitos encarcerados. Esta vigilância, direcionada aos prisioneiros, atua como um poder que faz naturalizar e memorizar leis e regras de conduta que devem ser seguidas rigorosamente. A mesma, não só age no sentido de adjetivar os encarcerados, mas também para classificá-lo, coisificá-lo e puni-lo.

Contudo, como toda construção sócio-histórica se encontra numa constante metamorfose, os homens e mulheres que compõem o socius apresentam uma gama de possibilidades e resistências que com o tempo fomentam a transformação da realidade. Assim, chega-se a duas certezas, os sujeitos não são totalmente autônomos diante desta instituição e esta não é algo inalterável e detentora de um poder absoluto.

Por se tratar de uma instituição que apresenta uma memória carregada de contradições, conflitos e de correlações de força, a prisão, por mais paradoxal que pareça, possibilita também a transformação e a criação em função da resistência ao poder que funciona como uma dobra de memória. O poder, enquanto forma de subjetivação e sujeição, abre espaço para as resistências que também são meios de produção de memória. Por conseguinte, torna-se necessário o questionamento no que tange a função e o papel da instituição prisão para que se consiga vislumbrar importantes valores que vêm sendo esquecidos na contemporaneidade: o novo, a criação.

R. Inter. Interdisc. INTERthesis, Florianópolis, v.13, n.1, p.01-20 Jan-Abr. 2016 


\title{
THE MEMORY DURING PRISON TIME: IN BETWEEN MASSIFICATION AND RESISTANCE
}

\begin{abstract}
:
This article aims to understand how the penitentiary institution can, through its dynamics, experiences and disciplinary practices, enable the balance of subjective differences from jailed people by the assimilation of living standards in terms of submission and obedience to the culture prison. As for the methodology used, the literature that aided the construction of this discussion and directed this work came from authors such as Foucault, Goffman, Thompson and Althusser directed such work. The phenomenon of "subjective massification" is present to the extent where institutions act in order to produce similar experiences in prison, turning them into traces of memories and souvenirs. Thus, the prison, like any other place of memory, conducts its incarcerated subjects according to a set of determinations established for the transmission of discipline and control. But the prison environment that acts in the pursuit of subjective standardization is based on contradictions and forces of correlations that also give way to resistance. Configuring, in that way, not only the preservation of the memory from that selected space, but also the production arrangements, or even better, a memory modality in terms of possible circumstances that require the power of the institution.
\end{abstract}

Keywords: Prison. Institution. Memory. Subjectivity. Resistance.

\section{LA MEMORIA EN LA PRISIÓN: ENTRE LA MASIFICACIÓN Y LA RESISTENCIA}

\section{Resumen:}

Este artículo tiene por objetivo comprender cómo la institución de la prisión puede, a través de su dinámica, experiencias y prácticas disciplinarias, trabajando con el fin de nivelar las diferencias subjetivas de los encarcelados por la asimilación de las normas de convivencia en términos de sumisión y obediencia a la cultura prisional. Dentro de la metodología utilizada, se realizó el levantamiento bibliográfico de obras que ayudasen en la construcción de esta discusión, donde autores como Foucault, Goffman, Thompson y Althusser orientan este trabajo. El fenómeno de la masificación subjetiva está presente en la medida en que la institución actúa para tratar de producir experiencias similares entre los encarcelados, convirtiéndolos en los vestigios de memoria y recuerdos. Así, la prisión como cualquier otro lugar de la memoria, conduce sus encarcelados de acuerdo con un conjunto de criterios establecidos para la transmisión de la disciplina y el control. De todos modos, el ambiente de la prisión, que actúa en la búsqueda de la normalización subjetiva está fundamentado en contradicciones y correlaciones de fuerzas que dan paso a la resistencia. Esto configura no sólo la preservación de la memoria del espacio instituído, sino también la producción de arreglos, o mejor, un modo de memoria en términos de posibles pliegues que requiere el poder de la institución.

Palabras clave: Prisión. Institución. Memoria. Subjetividad. Resistencia. 


\section{REFERÊNCIAS}

AGUIRRE, C. Cárcere e sociedade na América Latina, 1800-1940. Em: Maia, C. N. e outros (org.). História das prisões no Brasil., v.1. Rio de Janeiro: Rocco, 2009.

ALTHUSSER, Louis. Aparelhos ideológicos de Estado: nota sobre os aparelhos ideológicos de Estado (AIE). Rio de Janeiro: Edições Graal, 1918.

BARCINSKI, Mariana \& CUNICO, Sabrina Daiana. Rev. Psicologia: Ciência e Profissão., Os efeitos (in)visibilizadores do cárcere: as contradições do sistema prisional. Brasília, v.26, n. 4, 2006. Disponível em: $<$ http://www.scielo.br/scielo.php?script=sci_arttext\&pid=S141498932006000400002>. Acesso em 03 jun 2015.

BECCARIA, Cesare. Dos Delitos e das Penas. São Paulo: Martin Claret, 2001.

BENTHAM, Jeremy, O panóptico. Belo Horizonte: Autêntica, 2008.

BERGSON, Henri. Matéria e memória: ensaio sobre a relação do corpo com o espírito. São Paulo: Martins Fontes, 1990.

BERGER, Peter L.; LUCKMANN, Thomas. A construção social da realidade. Petrópolis: Vozes, Cap. 2 p. 67 -121, 2006.

BUTLER, Judith. Mecanismos psíquicos del poder. Valencia: Ediciones de Cátedra, 2011.

CASTEL, Robert. A Ordem Psiquiátrica: a Idade de Ouro do alienismo. Rio de Janeiro: Graal, 1978.

CASTEL, Robert. A Instituição Psiquiátrica em Questão. In Figueira, Sérvulo Augusto (coord.). Sociedade e Doença Mental. Rio de Janeiro: Campus, 1978. COSTA, Ilcéia. Memória Institucional: a construção conceitual numa abordagem teórico-metodológica. Rio De Janeiro: Universidade Federal do Rio de Janeiro, 1997 (Tese de Doutorado em Ciência da Informação).

DELEUZE, Gilles. Foucault. Tradução: Claúdia Sant'Anna Martins; São Paulo: Brasiliense, 2005. 
DORNELLES, J. R. O que é crime. São Paulo: Brasiliense, 1988.

FONSECA, Karina Prates da. (Re)Pensando o crime como uma relação de antagonismo entre seus autores e a sociedade. Rev. Psicologia: Ciência e Profissão., Brasília , v. 26, n. 4, dez. 2006 . Disponível em: $<$ http://www.scielo.br/scielo.php?script=sci_arttext\&pid=S1414-

98932006000400002\&lng=en\&nrm=iso>. Ācesso em: 25 jun 2015.

FOUCAULT, Michel. Microfísica do poder. Rio de Janeiro: Edições Graal, 1979.

FOUCAULT, Michel. Vigiar e Punir - História das violências nas prisões. Tradução de Raquel Ramalhete, 13 ed. RJ, Petrópolis: Vozes, 1987.

FOUCAULT, Michel. História da loucura: Na idade clássica. São Paulo: Perspectiva, 1996.

GUATTARI, Felix. \& ROLNIK, Suely. Micropolítica: cartografias do desejo. Petrópolis: Vozes, 1996

GOFFMAN, Erving. Manicômios, prisões e conventos. São Paulo: Perspectiva, 1974.

GONDAR, Jô. Lembrar e esquecer: desejo de memória. In: COSTA, I.; GONDAR, J. (Org.) Memória e espaço. Rio de Janeiro: 7 Letras, 2000.

JACÓ-VILELA, Ana. Maria, FERREIRA, Arthur. Arruda. Leal. \& PORTUGAL, Francisco. Teixeira. (Orgs.). História da Psicologia. Rumos e percursos. Rio de Janeiro: NAU Editora, 2005.

RICOEUR, Paul. Memória, História e Esquecimento. Campinas, SP: Editora da UNICAMP, 2007.

SEQUEIRA, Vania. Conselheiro, Por que o carcereiro não deixa as portas da prisão abertas?. Rev. Interações., São Paulo, v.9, n.18, dez. 2004. Disponível em: $<$ http://pepsic.bvsalud.org/scielo.php?pid=S1413-

29072004000200004\&script=sci_arttext>. Acesso em: 08 jun. 2015.

THOMPSON, Augusto. A questão penitenciária. Rio de Janeiro, Forense, 1980. 
WACQUANT, Loïc. O lugar prisão na nova administração da pobreza. Rev. Novos estudos - CEBRAP., São Paulo, n80, mat. 2008. Disponível em: $<$ http://www.scielo.br/scielo.php?script=sci serial\&pid=01013300\&lng=en\&nrm=iso >. Acesso em: 06 jun. 2015.

Artigo

Recebido em 08 de Julho de 2015

Aceito em 05 de Março de 2016

R. Inter. Interdisc. INTERthesis, Florianópolis, v.13, n.1, p.01-20 Jan-Abr. 2016 